\title{
Improved quality of life in patients with implanted cardiac resynchronization therapy devices
}

\author{
Marina Mihajlović*, Dora Fabijanović, Martina Lovrić Benčić, Ana Ljubas \\ University of Zagreb School of Medicine, University Hospital Centre Zagreb, Zagreb, Croatia
}

\begin{abstract}
Considering the fact that the implanted cardiac pacemaker can have a significant impact on a patient's life quality, the aim of the research was to determine how much the implantation of a cardiac resynchronization therapy (CRT) device really changes patients' life. The questionnaire SF-36 was used to test the subjective evaluation of life quality after the implantation of a CRT device on a sample of 50 participants. The hypothesis in the study was that the implantation of a CRT device improves tolerance of the physical activity, decreases the patient's dependency on the help of other people, correlates to the visible qualitative improvement of the social and family environment, and improves communication.
\end{abstract}

Received: $16^{\text {th }}$ Apr 2014

*Address for correspondence: Klinički bolnički centar Zagreb, Kišpatićeva 12, HR10000 Zagreb, Croatia.

Phone: +385-91-5402-768

E-mail: marina.mihaj@gmail.com
The results show that in regards to the bodily functioning, limitations due to body impediments, social functioning, mental health, vitality, body pain, and total perception of health, the quality of life was significantly improved statistically ( $p$ $<0.05$ ). The only exception was the domain of limitations due to emotional problems where there was no statistically significant difference after the implantation of a CRT device. There was no difference in relation to age, while in relation to gender there was a correlation to the total perception of health and changes in health, where statistically significant difference in the changes of life quality was observed in male patients.

This research proved that the total life quality in its various aspects improved significantly after the implantation of a CRT device, which was the starting hypothesis of the study.

KEYWORDS: heart failure, cardiac resynchronisation therapy, quality of life.

CITATION: Cardiol Croat. 2014;9(5-6):214.

\section{Literature}

1. Thoren E, Kesek M, Jideus L. The effect of concomitant cardiac resynchronization therapy on quality of life in patients with heart failure undergoing cardiac surgery. Open Cardiovasc Med J. 2014;8:18-22.

2. Kosmala W, Marwick TH. Meta-analysis of effects of optimization of cardiac resynchronization therapy on left ventricular function, exercise capacity, and quality of life in patients with heart failure. Am J Cardiol. 2014;113(6):988-94. 